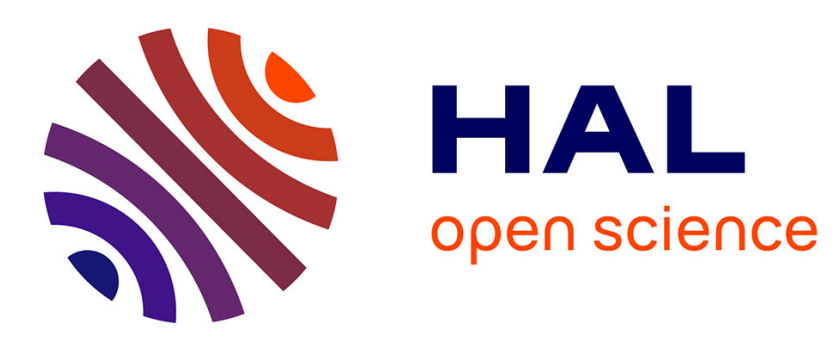

\title{
On some endogenous probability-migration models
}

\author{
Manuel Philippe Emile Garcon, Josselin Garnier, Abdennebi Omrane
}

\section{To cite this version:}

Manuel Philippe Emile Garcon, Josselin Garnier, Abdennebi Omrane. On some endogenous probability-migration models. Revue d'économie régionale et urbaine, 2013, 10.3917/reru.135.0877. hal-02504307

\section{HAL Id: hal-02504307 \\ https://hal.science/hal-02504307}

Submitted on 10 Mar 2020

HAL is a multi-disciplinary open access archive for the deposit and dissemination of scientific research documents, whether they are published or not. The documents may come from teaching and research institutions in France or abroad, or from public or private research centers.
L'archive ouverte pluridisciplinaire HAL, est destinée au dépôt et à la diffusion de documents scientifiques de niveau recherche, publiés ou non, émanant des établissements d'enseignement et de recherche français ou étrangers, des laboratoires publics ou privés. 


\title{
A propos de quelques modèles de flux migratoire avec probabilité endogène
}

\author{
On some endogenous \\ probability-migration models
}

\author{
Manuel GARCON \\ Ceregmia et Université des Antilles et de la Guyane \\ manuel.garcon@gmail.com \\ Josselin GARNIER \\ Laboratoire de Probabilités et Modèles Aléatoires \\ Laboratoire Jacques-Louis Lions et Université Paris VII \\ garnier@math.jussieu.fr
}

\section{Abdennebi OMRANE*}

Ceregmia et Université des Antilles et de la Guyane aomrane@univ-ag.fr

Mots clef : capital humain, croissance économique, incertitude, migration, point fixe

Keywords : economic growth, fixed point, human capital, indeterminacy, migration

Classification JEL : F22 ; J24 


\section{Résumé}

Nous analysons un modèle probabiliste de migration dans lequel la probabilité de migration dépend du capital humain, comme l'établit CHEN (2008). Nous montrons que le capital humain peut converger vers une valeur faible ou élevée en fonction non seulement de la dépendance fonctionnelle de la probabilité de la migration sur le capital humain, mais aussi en fonction des conditions initiales du capital humain et des croyances de la population. Grâce à de nouveaux mécanismes de sélection dans le modèle, nous analysons précisément comment les économies ayant des antécédents similaires peuvent suivre des équilibres différents parce que leurs agents économiques ont des croyances différentes quant à leur probabilité de migration dans le futur.

\section{Abstract}

We analyze a probability-migration model in which the probability of migration depends on human capital, as produced by CHEN (2008). We show that the human capital can converge to a low or high value depending not only on the functional dependence of the probability of migration on human capital, but also on the initial human capital conditions and on beliefs of the population. Thanks to some new selection mechanisms of migration, we analyze precisely how economies with similar backgrounds may follow different equilibrium paths because their economic agents have different beliefs about their future probability of migration.

\section{-1 - \\ Introduction}

We are interested in the spatial economy in the sense where one considers at least two geographical places where can be carried out a migration of the individuals. We study here a mathematical model produced by Chen related to the probability of migration from a country A towards a country B. Work founders of the economic analysis of the decision to migrate place the search of better returned like an essential reason for the decision of migration: see HICKS (1932), SJAASTAD (1962), and see BHAGWATI and RODRIGUEZ (1975), WILSON (2008), LIEN and WANG (2005), MOUNTFORD (1997) and also DOCQUIER et al. (2007) for "Brain-Drain" litterature.

But other reasons can influence the individuals in their decision. KRUGMAN (1991) was interested in the mobility of the workers in Europe and their integration which would facilitate their migration. On the regional migration, ZENOU (2010) developed a model on the rural urban migration taking into account other endogenous parameters. The search of a more pleasant framework of life, of a culture or a more lenient climate are reasons likely to reinforce the choice of migration. Moreover, even if the migration can make it possible to the individual to reach a better situation, other factors can force this decision obviously.

The choice to migrate thus seems the result of an "arbitration" between the anticipated profits in the new situation obtained after the consecutive migration and costs with this decision and "probability models" may apply. It seems obvious that in this arbitration the weight of these elements can differ from one individual to another according to his preferences and from his objectives, which depend themselves on the life cycle of the individual. See for this Sanchez (2011), DE LA Croix (2003), 
STARK et al. (1998) and STARK et al. (2002). Considering here two periodes $t$ and $t+1$, the individuals are able to migrate if their human capital (primarily education) is high in a sense that we will describe below. CHEN's work (2006) is the first model where the probability of migration is endogenous. Here, the migration influences the level of human capital (education) of the country of origin. Choices to invest in education or not acted on the formation of the human capital in the country of origin.

Education is very important because it facilitates the migration of the individuals wishing to migrate from a country A towards another country B. Unlike HICKS (1932), the wages in our article are less important parameters, hence, education is an essential factor in the study of migration of the individuals here. An interesting example is that of the migration between Mexico and the USA. A study of CAPONI (2006) shows that the individuals with a very high level of education and those with a very low level of education are more numerous to migrate than those with an average level of education.

The probability of migration of a developing country depends on the economic growth in an essential way, since people living in a source country with higher average human capital are traditionally more incited to emigrate to a foreign country than those living in a source country with lower average human capital. CHEN (2006) and VIDAL (1998) proposed to endogenize the probability of migration and to make it, naturally, dependent on human capital. In CHEN (2006), an economic model is introduced in which the probability of migration can take only two values: the low (respectively high) value is taken when the human capital is smaller (respectively larger) than a threshold level. In this model there is a possibility of club convergence occurring in the short run, and conditional convergence occurring in the long run following the two possible scenarii:

The first scenario is when the probability of migration depends on prior human capital, which is the one inherited from the parents or equivalently the one of the agents before their education period; we call it in this paper the traditional case. In this scenario, the threshold level affects the economic behavior in the long run. More exactly, if the human capital threshold is sufficiently low (respectively high), then the economy converges to a high (respectively low) steady state level. However, if the human capital threshold is at the median level, club convergence may occur and the initial condition matters.

In the second scenario, the probability of migration depends on current human capital, which is the one of the agents at the end of their education period; we call it the anticipative case. In this scenario, the dynamic transition of the economy is determined by perceptions of the future. In CHEN (2006) it is found that a belief in the higher probability of migration in the future provides an incentive for agents to invest more in their education, thereby raising their accumulation of human capital, which in turn lead to a higher probability of migration. These heuristic arguments indicate that beliefs can change the picture in the anticipative case. 
In our article we show that migration can be used to explain some important economic growth phenomena. The two scenarii introduced above give rise to two distinct lines of research in the literature on economic growth:

The occurrence of multiple steady states in the first scenario can help to explain the findings of club convergence in the empirical studies.

The second scenario indicates that migration can be a source of indeterminacy, and therefore emphasizes the role of beliefs. This implies that when embracing migration, economies with similar backgrounds may well follow different equilibrium paths simply because they have different beliefs about their future probability of migration.

The model that we address allows for a detailed analysis and exhibits the relevant features.

\section{- 2 - \\ Position of the problem}

In a small open economy characterized by an infinite horizon, CHEN (2006) considers a no-growth overlapping generations model, where agents live for two successive periods. In each period a new generation is born, agents born in period $t$ are endowed with parental human capital $h_{t}$ and are supposed to allocate their time between gaining education and engaging in leisure in the first period of life. In the second period, agents can migrate to a foreign country (country $B$ ) with probability $\mathrm{p}_{\mathrm{t}} \in[0,1]$ or remain into the home country (country $A$ ) with probability $1-\mathrm{p}_{\mathrm{t}+1}$. During this second period of life, agents spend all of their time working to earn income for consumption.

Moreover, if $\mathrm{w}_{\mathrm{A}}$ and $\mathrm{w}_{\mathrm{B}}$ represent the respective real wage per unit of human capital in countries $A$ and $B$, the earnings of agents are equal to their level of human capital multiplied by the real wage per unit of human capital of the country in which they live. That is, the expected utility function, which is identical for all agents, is defined for $\beta>0$ and $\theta>1$ by:

$$
\mathrm{u}_{\mathrm{t}}=\ln \left(1-\mathrm{e}_{\mathrm{t}}\right)+\beta\left[\left(1-\mathrm{p}_{\mathrm{t}+1}\right) \ln \left(\mathrm{w}_{\mathrm{A}}+\mathrm{h}_{\mathrm{t}+1}\right)+\mathrm{p}_{\mathrm{t}+1} \theta \ln \left(\mathrm{w}_{\mathrm{B}}+\mathrm{h}_{\mathrm{t}+1}\right)\right]
$$

As in CHEN (2006), from period $t$ to period $t+1$ the human capital evolves following the relation

$$
h_{t+1}=A e^{\gamma} h_{t}^{\delta} \gamma, \delta \in(0,1)
$$

We distinguish two migration processes: the traditional process of migration in which the probability of migration is defined as $\mathrm{p}_{\mathrm{t}+1}=\mathrm{P}\left(\mathrm{h}_{\mathrm{t}}\right)$, where $\mathrm{P}$ is an increasing function, and the anticipative process in which the probability of migration is defined as $\mathrm{p}_{\mathrm{t}+1}=\mathrm{P}\left(\mathrm{h}_{\mathrm{t}+1}\right)$. In the traditional process the probability of migration of the young 
adults $\mathrm{p}_{\mathrm{t}+1}$ is determined by the human capital of their parents $\mathrm{h}_{\mathrm{t}}$. In the anticipative process the probability of migration of the young adults $\mathrm{p}_{\mathrm{t}+1}$ is determined by the human capital of the young adults at the end of their first period $h_{t+1}$. As we will see, indeterminacy can occur in this anticipative situation, since the time spent in education $e_{t}$, and therefore the human capital of the young adults at the end of their first period $\mathrm{h}_{\mathrm{t}+1}$, then depend on the probability of mutation $\mathrm{p}_{\mathrm{t}+1}$. Indeed, the variation of the utility function with respect of the education function is given by:

(3) $\frac{\partial u_{t}}{\partial e_{t}}=\frac{-1}{1-e_{t}}+\beta\left[\left(1-p_{t+1}\right) \frac{\gamma}{e_{t}}+\theta p_{t+1} \frac{\gamma}{e_{t}}\right]$

and the optimal decision which is reached at is given by:

$$
e_{t}^{*}=\frac{\gamma \beta\left[1+(\theta-1) p_{t+1}\right]}{1+\gamma \beta\left[1+(\theta-1) p_{t+1}\right]}
$$

\section{The traditional model}

The probability of migration is assumed to be dependent on average human capital. We suppose that if the agents are homogeneous, then the average human capital is equal to the personal human capital in each period. In this subsection, we consider the traditional model of migration, that is:

(5) $\quad \mathrm{p}_{\mathrm{t}+1}=\mathrm{P}\left(\mathrm{h}_{\mathrm{t}}\right)$

which means that the probability of migration is dependent on average human capital lagged by one period (i.e. the average human capital of the parents). We also suppose that:

$$
\mathrm{p}\left(h_{t}\right)=\left\{\begin{array}{l}
p_{1} \text { if } h_{t}<h^{\#} \\
p_{2} \text { if } h_{t}>h^{\#}
\end{array}\right.
$$

for some probability constants $0 \leqslant \mathrm{p}_{1}<\mathrm{p}_{2} \leqslant 1$, where $\mathrm{h}^{\#}$ is a nominative threshold human capital as in CHEN (2006). For $j=1,2$, we finally denote

(7) $\quad e_{j}=\frac{\gamma \beta\left[1+(\theta-1) p_{j}\right]}{1+\gamma \beta\left[1+(\theta-1) p_{j}\right]} j=1,2$

Note that we have $e_{1}<e_{2}$. 
Proposition 1 The sequence of human capitals converge to a fixed point as $t \rightarrow \infty$. The two possible fixed points $\underline{\mathrm{h}}_{1}$ and $\underline{\mathrm{h}}_{2}$ defined by

(8) $\quad \bar{h}_{j}=\left(A e_{j}^{\gamma}\right)^{\frac{1}{1-\delta}}, j=1,2$

We have the following:

- If $\underline{h}_{1>} h^{\#}$, then the sequence $\left(h_{t}\right)_{t}$ converges to $\underline{h}_{2}$ for every $h_{0}$.

- If $\underline{h}_{2}<h^{\#}$, then the sequence $\left(h_{t}\right)_{t}$ converges to $\underline{h}_{1}$ for every $h_{0}$.

- If $\underline{\mathrm{h}}_{1}<\mathrm{h}^{\#}<\underline{\mathrm{h}}_{2}$, then

(a) if $h_{0}<h^{\#}$, the sequence $\left(h_{t}\right)_{t}$ converges to $\underline{h}_{1}$,

(b) if $\mathrm{h}_{0}>\mathrm{h}^{\#}$, the sequence $\left(\mathrm{h}_{\mathrm{t}}\right)_{\mathrm{t}}$ converges to $\underline{\mathrm{h}}_{2}$.

This proposition is an application of standard results on the convergence of sequences defined by a recursive relation of the form:

$$
h_{t+1}=\left\{\begin{array}{l}
A e_{1}^{\gamma} h_{t}^{\delta} \text { if } h_{t}<h^{\#} \\
A e_{2}{ }^{\gamma} h_{t}^{\delta} \text { if } h_{t}>h^{\#}
\end{array}\right.
$$

With this traditional migration model (i.e. when the probability of migration is dependent on the human capital of the parents), the human capital threshold determines the growth of the economy which will converge to one of the two fixed points and given by (10).

\section{-4 - \\ The anticipative model}

In this section, we assume that the probability of migration is dependent on the average human capital in period $t+1$ CHEN (2006) and CIPRIANI and MAKRIS (2006) :

$$
p_{t+1}=P\left(h_{t+1}\right)
$$

with $P$ defined by (6). Then (9) becomes an implicit relation (ht +1 is on the right and on the left of the relation):

$$
h_{t+1}=\left\{\begin{array}{l}
A e_{1}^{\gamma} h_{t}^{\delta} \text { if } h_{t+1}<h^{\#} \\
A e_{2}^{\gamma} h_{t}^{\delta} \text { if } h_{t+1}>h^{\#}
\end{array}\right.
$$


Figure 1 - The traditional case: the solid line plots recursive formula (11).

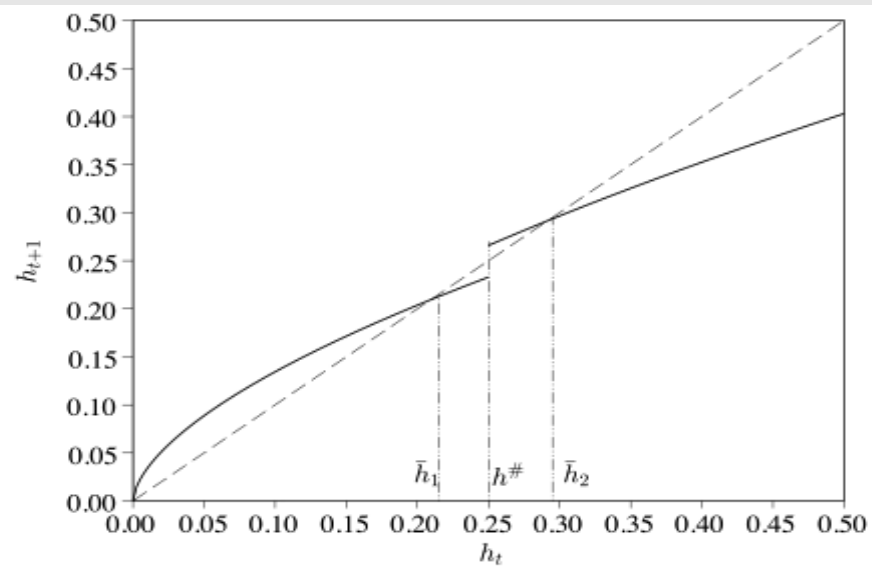

$\bar{h}_{1}<h^{\#}<\bar{h}_{2}$

Let us define:

$$
h_{o}^{\#}=\left(\frac{h^{\#}}{A e_{2}^{\gamma}}\right)^{\frac{1}{\delta}} \text { and } h_{p}^{\#}=\left(\frac{h^{\#}}{A \theta_{1}^{\gamma}}\right)^{\frac{1}{\delta}} \text {. }
$$

Note that we have:

$$
h_{o}^{\#}<h^{\#}<h_{p}^{\#} .
$$

Equation (11) is implicit and, given the value $h_{t}$, there may be several possible values for $h_{t+1}$. This shows that the dynamics of human capital depends on households perceptions and beliefs about the future. The following lemma addresses the easy situation in which there is no indeterminacy.

Lemma 2 Let be $h_{t}$ the human capital at period t. Then the human $h_{t+1}$ capital at period $t+1$ must satisfy equation (11). Then we have the following:

1) If $h_{t}<h_{o}^{\#}$ then there exists a unique possible value $h_{t+1}=A e_{1}{ }^{\gamma} h_{t}^{\delta}$.

2) If $h_{t}>h_{p}^{\#}$ then there exists a unique possible value $h_{t+1}=A e_{2}{ }^{\gamma} h_{t}^{\delta}$.

The proof of Lemma 2 is easy and follows from (13) and (9). 
From now on in this paper we consider the case in which the following hypothesis is fulfilled by the parameters of our model:

$$
e_{1}^{\gamma(\delta-1)} e_{2}^{-\gamma \delta}<A\left(h^{\#}\right)^{\delta-1}<e_{1}^{-\gamma \delta} e_{2}^{\gamma(\delta-1)}
$$

We now discuss useful equivalent formulations of Hypothesis (14) and a convergence result in the following proposition:

Proposition 3 Hypothesis (14) is fulfilled if and only if

$$
\left[0, h_{o}^{\#}\right) \text { and }\left(h_{p}^{\#},+\infty\right) \text { are stable }
$$

if and only if the two possible fixed points given by (8) satisfy

(16) $h_{1} \in\left[0, h_{o}^{\#}\right)$ and $\underline{h_{2}} \in\left(h_{p}^{\#},+\infty\right)$.

Moreover, if (14) is satisfied, and if $h_{0}$ is the initial human capital, then we have the following assertions:

1.If $h_{0}<h_{o}^{\#}$ then the resulting human capital sequence converges to the fixed point $\underline{h}_{1}$.

2.If $h_{0}>h_{p}^{\#}$ then the resulting human capital sequence converges to the fixed point $\underline{\mathrm{h}}_{2}$.

The complementary case of (14) is addressed in GARÇON (2013). Hypothesis (14) ensures the stability of the intervals $\left[0, h_{o}^{\#}\right)$ and $\left(h_{p}^{\#},+\infty\right)$ and through the anticipative model (11), and shows that the two fixed points belong to the two different stable regions. Moreover, Proposition 3 states that stability and existence of the two fixed points in the stable regions implies convergence of the sequence defined by (11).

The proof of Proposition 3 is given in the Appendix. We need now to address the case in which lemma.

$h_{o}^{\#}<h_{0}<h_{p}^{\#}$. In this case indeterminacy occurs, as stated in the following

Lemma 4 Let $h_{t}$ be the human capital at period t. If $h_{o}^{\#}<h_{t}<h_{p}^{\#}$, then there exist two different possible values for the solution $h_{t+1}$ of (11):

$$
\text { (17) } h_{t+1, j}=A e_{j}^{\gamma} h_{t}^{\delta} \text { for } j=1,2
$$


The lemma shows that it is necessary to give a mechanism to select between the two possible solutions for $h_{t+1}$ in the case in which $h_{o}^{\#}<h_{t}<h_{p}^{\#}$. We will address different selection mechanisms in Subsection 4.1 and Subsection 4.2 below.

\subsection{Optimistic and pessimistic selection mechanisms}

The pessimistic selection mechanism consists in choosing the smallest value for the human capital when there are two possible choices. The optimistic selection mechanism consists in choosing the largest value for the human capital when there are two possible choices. These are the two extremal selection mechanisms. We will consider an intermediate mechanism later in subsection 4.1.

The following proposition gives the main result in the case of the two selection mechanisms.

Proposition 5 Let $h_{0}$ be an initial human capital in the multivalued region i.e $h_{o}^{\#}<h_{0}<h_{p}^{\#}$. We have the following assertions:

1.With the pessimistic selection mechanism, the sequence $\left(h_{t}\right)_{t}$ converges to the fixed point $\underline{\mathrm{h}}_{1}$ if $h_{0}<h_{p}^{\#}$, and converges to the fixed point $\underline{\mathrm{h}}_{2}$ if $h_{0}>h_{p}^{\#}$.

2.With the optimistic selection mechanism, the sequence $\left(h_{t}\right)_{t}$ converges to the fixed point $\underline{\mathrm{h}}_{1}$ if $h_{0}<h_{o}^{\#}$, and converges to the fixed point $\underline{\mathrm{h}}_{2}$ if $h_{0}>h_{o}^{\#}$.

This proposition shows that the threshold value for the initial condition below which the human capital converges to the low fixed point is smaller with the optimistic mechanism than with the pessimistic mechanism.

\subsection{Conservative selection mechanism}

We still use Hypothesis (14). The conservative selection mechanism consists in choosing for the human capital $h_{t+1}$ at period $t+1$ the value that is the closest from $h_{t}$ when there are two possible choices.

Let us define $(18) h_{c}^{\#}=\left(A \frac{e_{1}^{\gamma}+e_{2}^{\gamma}}{2}\right)^{\frac{1}{1-\delta}}$.

Then we have the following Lemma : 
Lemma 6 Let $h_{0}$ be an initial human capital in the multivalued region i.e $h_{o}^{\#}<h_{0}<h_{p}^{\#}$. We have the two following assertions:

(a) If $h_{0}>h_{c}^{\#}$, then we have $h_{\mathrm{t}}>h_{c}^{*}$ for all $\mathrm{t}$ and $h_{t+1}=A e_{2}{ }^{\gamma} h_{t}^{\delta}$ is the solution selected by the conservative mechanism. Moreover, the sequence $\left(h_{t}\right)_{t}$ converges to the fixed point $\underline{\mathrm{h}}_{2}$

(b) If $h_{0}<h_{c}^{\#}$, then we have $h_{t}<h_{c}^{\#}$ for all $\mathrm{t}$ and $h_{t+1}=A e_{1}{ }^{\gamma} h_{t}^{\delta}$ is the solution selected by the conservative mechanism. Moreover, the sequence $\left(h_{t}\right)_{t}$ converges to the fixed point $\underline{\mathrm{h}}_{1}$.

We recall that the threshold value in the traditional case is $h^{\#}$. In the anticipative case with the optimistic (resp. pessimistic) selection mechanism it is $h_{o}^{\#}$ (resp. $h_{p}^{\#}$ ). The following proposition summarizes the convergence results when the conservative selection mechanism is used:

Proposition 7 With the conservative selection mechanism, the sequence $\left(h_{t}\right)_{t}$ converges to the fixed point $\underline{\mathrm{h}}_{1}\left(\right.$ resp. $\left.\underline{\mathrm{h}}_{2}\right)$ if $h_{0}<H$ (resp. $h_{0}>H$ ) where we have:

(a) $H=h_{p}^{\#}$ if $h_{c}^{\#}>h_{p}^{\#}$,

(b) $H=h_{o}^{\#}$ if $h_{c}^{\#}<h_{o}^{\#}$,

(c) $H=h_{c}^{\#}$ if $. h_{o}^{\#}<h_{c}^{\#}<h_{p}^{\#}$.

To have a high economy level, we notice that the optimistic anticipation mechanism is the one that gives the smallest threshold value $H$ from which we have convergence to the highest fixed point. Conversely, the pessimistic anticipation mechanism is the one that gives the largest threshold value.

\section{- 5 - \\ Conclusion}

It is worthwhile to note that, whatever the type of evolution equation for the human capital (traditional or anticipative) and for any selection mechanism, the result can always be expressed by an assertion of the form: if the initial capital $h_{0}$ 
is smaller than a threshold value $H$, then the human capital will converge to the low fixed point $\underline{h}_{1}$, while if the initial capital $h_{0}$ is larger than a threshold value $H$, then the human capital will converge to the high fixed point $\underline{h}_{2}$. The values of the fixed points $\underline{h}_{1}$ and $\underline{h}_{2}$ do not depend on the type of evolution equation and on the selection mechanism. Only the threshold value $H$ depends on the type of evolution equation and on the selection mechanism. In particular we show that beliefs can have a strong impact on the threshold value $H$.

\section{-6 -}

\section{Appendix: Proofs and complementary results}

Proof of Proposition $3:\left[0, \mathrm{~h}_{\mathrm{o}}^{\#}\right)$ in (15). Let $h_{t}$ be such that $h_{t}<h_{o}^{\#}$. This is equivalent to $e_{2}{ }^{\gamma} h_{t}^{\delta}<h^{\#}$.

From Lemma 2 we have $h_{t+1}=A e_{1}{ }^{\gamma} h_{t}^{\delta}$. Using the RHS of Hypothesis (14) we have :

$$
A\left(h^{\#}\right)^{\delta-1}<e_{1}{ }^{-\gamma \delta} e_{2}{ }^{\gamma(\delta-1)} \text { which is equivalent to } A e_{1}^{\gamma}<\left(\frac{h^{\#}}{A e_{2}^{\gamma}}\right)^{\frac{1-\delta}{\delta}} \text {. }
$$

This implies:

$$
h_{t+1}=A e_{1}^{\gamma} h_{t}^{\delta}<\left(\frac{h^{\#}}{A e_{2}^{\gamma}}\right)^{\frac{1-\delta}{\delta}} h_{t}{ }^{\delta}=\left(\frac{A e_{2}^{\gamma} h_{t}^{\delta}}{h^{\#}}\right) h_{o}^{\#}<h_{o}^{\#}
$$

which proves the stability of the interval $\left[0, h_{o}^{\#}\right)$.

For the stability of the interval $\left(h_{p}^{\#},+\infty\right)$ we use the same type of arguments: if $h_{t}>h_{p^{\prime}}^{\#}$ then we use the LHS of Hypothesis (14), i.e $e_{1}{ }^{\gamma(\delta-1)} e_{2}{ }^{-\gamma \delta}<A\left(h^{\#}\right)^{\delta-1}$ to prove that $h_{t}>h_{p}^{\#}$.

Now we prove (16). We have the following equivalence with (14):

$$
A\left(h^{\#}\right)^{\delta-1}<\left(e_{1}^{\gamma}\right)^{-\delta}\left(e_{2}^{\gamma}\right)^{\delta-1} \text { iff }\left(A e_{1}^{\gamma}\right)^{\delta}<\left(\frac{h^{\#}}{A e_{2}^{\gamma}}\right)^{1-\delta} \text { iff } \bar{h}_{1}<h_{o}^{\#}
$$

and 


$$
A\left(h^{\#}\right)^{1-\delta}>e_{1}^{\gamma(\delta-1)} e_{2}^{-\gamma \delta} \text { iff }\left(A e_{2}^{\gamma}\right)^{\delta}>\left(\frac{h^{\#}}{A e_{1}^{\gamma}}\right)^{1-\delta} \text { iff } \bar{h}_{2}>h_{p}^{\#}
$$

We end by proving the convergence result:

Case (1): If $h_{0}<h_{0}^{\#}$ the above stability result shows that for all $t$ we have $h_{t}<h_{o}^{\#}$, which defines $h_{t+1}=A e_{1}{ }^{\gamma} h_{t}^{\delta}$ by Lemma 2 . Therefore, the sequence $\left(h_{t}\right)_{t}$ converges to the fixed point, which is the unique fixed point of the recursive relation $h_{t+1}=A e_{1}^{\gamma} h_{t}^{\delta}$ in $\left[0, h_{o}^{\#}\right)$ by (16).

Case (2) The same type of arguments can be used and the result holds true.

Proof of Proposition 5: (Case 1) If $h_{0}<h_{p}^{\#}$ then we can show $h_{t}<h_{p}^{\#}$ by induction that for all $t$ we have $h_{t}<h_{p}^{\#}$ and $h_{t+1}=A e_{1}^{\gamma} h_{t}^{\delta}$. Indeed, if $h_{t}<h_{p}^{\#}$, then the pessimistic mechanism selects $h_{t+1}=A e_{1}^{\gamma} h_{t}^{\delta}$ and therefore $h_{t+1}<A e_{1}^{\gamma}\left(h_{p}^{\#}\right){ }^{\delta}=h^{\#}<h_{p}^{\#}$. Note that this argument also shows that $h_{t}<h^{\#}$ as soon as $t \geqslant 1$. Since $\underline{h}_{1}$ is the unique fixed point of the recursive relation $h_{t+1}=A e_{1}^{\gamma} h_{t}^{\delta}$ in $\left[0, h_{o}^{\#}\right)$, the sequence $\left(h_{t}\right)_{t}$ must converge to the fixed point $\underline{h}_{1}$.

From the other side, if $h_{0}>h_{p}^{\#}$ then by applying Proposition 3, we find that the sequence $\left(h_{t}\right)_{t}$ converges to the fixed point $\underline{h}_{2}$.

Case (2) can be addressed in the same way.

Proof of Lemma 6:Let the initial condition be such that: $h_{o}^{\#}<h_{0}<h_{p}^{\#}$.

In case (a) we have $h_{0}>h_{c}^{\#}$. By induction we can show that $h_{t}>h_{c}^{\#}$ and $h_{t+1}=A e_{2}^{\gamma} h_{t}^{\delta}$ for all $t$. Indeed, if $h_{t}>h_{c}^{\#}$, then we have two possible solutions by Lemma $4: h_{t+1,1}=A e_{1}^{\gamma} h_{t}^{\delta}$ and $h_{t+1,2}=A e_{2}{ }^{\gamma} h_{t}^{\delta}$. However $h_{t}>h_{c}^{\#}$ is equivalent to $2 h_{t}>A\left(e_{1}^{\gamma}+e_{2}^{\gamma}\right) h_{t}^{\delta}$, and therefore we have $h_{t}-h_{t+1,1}>h_{t+1,2}-h_{t}>0$. Consequently the conservative mechanism selects $h_{t+1,2}$. This point is larger than $h_{t}$, which is itself larger than $h_{c}^{\#}$, which completes the proof of the induction. Finally, the unique fixed point of the recursive relation in $h_{t+1}=A e_{2}^{\gamma} h_{t}^{\delta}$ in $\left(h_{c}^{\#},+\infty\right)$ is $\underline{h}_{2}$ by (16). Therefore the sequence $\left(h_{t}\right)_{t}$ must converge to $\underline{h}_{2}$. We use the same arguments for the proof of Case (b).

Remark 8:

To be complete we mention that cases (a) and (b) in Lemma 6 can indeed occur. 
More exactly, case (a) occurs if $h_{c}^{\#}<h_{p}^{\#}$. Case (b) occurs if $h_{c}^{\#}>h_{o}^{\#}$. The fact that $h_{c}^{\#}<h_{p}^{\#}$ is equivalent to $\left(h^{\#}\right)^{\delta-1}<e_{1}{ }^{-\gamma \delta} e_{2}{ }^{\gamma(\delta-1)}$, which is compatible with

Hypothesis (14). The fact that $h_{c}^{\#}>h_{o}^{\#}$ is equivalent to $\left(h^{\#}\right)^{\delta-1}>e_{1}{ }^{-\gamma \delta} e_{2}{ }^{\gamma(\delta-1)}$, which is also compatible with Hypothesis (14).

\section{References}

BHAGWATI J, RODRIGUEZ C (1975) Welfare-Theoretical Analysis of the Brain Drain. Journal of Development Economics 2: 195-221.

CAPONI V (2006) Heterogeneous human capital and migration: Who migrates from Mexico to the US? IZA DP 2446, Discussion Paper Series, Bonn, Germany.

CHEN H J (2008) The endogenous probability of migration and economic growth. Economic Modelling $25: 1111-1115$.

CHEN H J (2006) International migration and economic growth: a source country perspective. Journal of Population Economics 19 : 725-748.

CIPRIANI G P, MAKRIS M (2006) A model with self-fulfilling prophecies of longevity. Economics Letters $91: 122-126$.

De La Croix D, Doepke M (2003) Inequality and Growth: Why Differential Fertility Matters. American Economic Review 93 : 1091-113.

DocQuier F, Lohest O, MARfouk A (2007) Brain Drain in Developing Countries. World Bank Economic Review $21: 193-218$.

GARÇON M (2013) Analyse mathématique et économique des problèmes de flux migratoires. Phd Thesis, Université des Antilles et de la Guyane.

HICKS J R (1932) The theory of wages. Londres, Macmillan.

KRUGman P (1991) Increasing Returns and Economic Geography. The Journal of Political Economy, Volume 99, $3: 483-499$.

LIEN D, WANG Y (2005) Brain Drain or Brain Gain: A Revisit. Journal of Population Economics, 18 : 153-163.

MOUNTFORD A (1997) Can a brain drain be good for growth in the source economy?. Journal of Development EConomics 53 (2) : 287-303.

SANCHEZ Caldera A, ANDREWs D (2011) To Move or not to Move: What Drives Residential Mobility Rates in the OECD?. OECD Economics Department Working Papers 846, OECD Publishing.

SJAASTAD A L (1962) The Costs and Returns of Human Migration. Journal of Political Economy 70 (5) : 80-93.

STARK O, WANG Y (2002) Inducing human capital formation: migration as a substitute for subsidies. Journal of Public Economics 86 (1) : 29-46.

Stark O, Helmenstein C, Prskawetz a (1998) Human capital depletion, human capital formation and migration: a blessing or a curse?. Economic Letters 60 (3) : 363-367.

VIDAL J P (1998) The effect of emigration on human capital formation. Journal of Population Economics 11 (4) : 589-600.

WILSON J D (2008) A voluntary brain-drain tax. Journal of Public Economics 92 (12) : 2385-2391.

ZeNOU Y (2010) Search, Migration, and Urban Land Use: The Case of Transportation Policies. IZA Discussion paper series, 5312. 